\title{
Studies on efficient rehydration of dried green peas (Pisum sativum)
}

Shweta Saloni, Sindhu, Sujata and Aditi Singh

Received : 10.04.2018; Accepted : 13.04.2018

See end of the Paper for authors' affiliation

Correspondence to :

Shweeta Saloni Department of Food Processing and Technology, UTD, Bilaspur University, Bilaspur (C.G.) India
- Abstract : This study investigates efficient rehydration of dried green peas for its use in "Heat and Eat" food products. Dehydration and rehydration kinetics of green peas were studied on Hot Air Dryer (HAD) and Solar Conduction Dryer (SCD) for untreated and pre-treated samples. The two pre-treatments used were 1. Partial cuts on the surface, followed by steaming for 2 mins and 2.Blanching in $1 \% \mathrm{Na}_{2} \mathrm{CO}_{3}$ solution for 2 mins. Rehydration was carried out under conditions of varying temperature $\left(50,70\right.$ and $\left.90^{\circ} \mathrm{C}\right)$ and time (5 and 10 mins). Hardness, Rehydration Ratio and Colour ( $\mathrm{L}^{*} \mathrm{a} * \mathrm{~b} *$ values) was measured for fresh, dried and rehydrated samples to find the optimum pre-treatment and drying method for efficient rehydration. Partial surface cuts followed by steaming was found to be the better pre-treatment for both HAD and SCD dried peas whereas colour after rehydration was better retained in HAD dried peas."

- Key words : Rehydration, Dried peas, $\mathrm{Na}_{2} \mathrm{CO}_{3}$

- How to cite this paper : Saloni, Shweta, Sindhu, Sujata and Singh, Aditi (2018). Studies on efficient rehydration of dried green peas (Pisum sativum). Internat. J. Agric. Engg., 11(Sp. Issue) : 15-21, DOI: 10.15740/HAS/IJAE/11.Sp. Issue/15-21. 